\title{
Mechanisms of gastro-oesophageal reflux in cystic fibrosis
}

\author{
S Cucchiara, F Santamaria, M R Andreotti, R Minella, P Ercolini, V Oggero, G de Ritis
}

\begin{abstract}
Abnormal degrees of gastro-oesophageal reflux (GOR) were detected by 24 hour intraoesophageal pH measurement in 12 of 14 children (mean age 7.9 years; range 5 months16 years) affected by cystic fibrosis and complaining of symptoms suggesting GOR. These patients underwent combined recording of distal oesophageal motility and intraluminal pH in order to investigate mechanisms of GOR. Inappropriate lower oesophageal sphincter relaxation was the most common mechanism of reflux in all patients. Other mechanisms (appropriate relaxation or lowered pressure of the lower oesophageal sphincter, increased intragastric pressure) were detected less frequently. Frequency of inappropriate lower oesophageal sphincter relaxations was significantly higher in patients with cystic fibrosis than in other study groups (symptomatic GOR, GOR disease complicated by respiratory complaints). Inappropriate lower oesophageal sphincter relaxations occurred with the same frequency in patients with cystic fibrosis and in a group of children with GOR disease complicated by oesophagitis. Abnormalities of distal oesophageal contractions such as decreased amplitude or uncoordinated waves were also recorded in cystic fibrosis patients. Seven patients with cystic fibrosis completed a therapeutic trial for eight weeks consisting of postural treatment and oral cisapride, a new prokinetic drug. The oesophageal acid exposure improved in only three patients. We conclude that pathologic GOR is commonly asssociated with cystic fibrosis. The predominant reflux mechanism in these patients is a transient inappropriate lower oesophageal sphincter relaxation rather than a low steady state basal lower oesophageal sphincter pressure.
\end{abstract}

Department of Paediatrics,

2nd School of Medicine, University of Naples, Italy

S Cucchiara

F Santamaria

M R Andreotti

$R$ Minella

P Ercolini

V Oggero

G de Ritis

Correspondence to: Dr Salvatore Cucchiara, Dipartimento di Pediatria II Facoltà di Medicina, Via S Pansini 5 ,

80131 Napoli,

Italia.

Accepted 15 November 1990 worsen chronic pulmonary disease in these patients. $^{6-9}$

The purposes of this study were to document the incidence of pathologic GOR in a group of patients with cystic fibrosis with symptoms suggesting GOR and to evaluate mechanisms responsible for reflux in the same patients.

\section{Patients and methods}

Fourteen patients with cystic fibrosis (mean age 7.9 years, range 5 months-16 years) and symptoms suggesting GOR such as heartburn, dysphagia, and regurgitation and/or vomiting underwent both prolonged intra-oesophageal $\mathrm{pH}$ monitoring and combined intraoesophageal manometric and $\mathrm{pH}$ recordings. All patients had mild to moderate respiratory disease. The mean Chrispin-Norman score on the last chest radiograph was 12 (range $4-21)^{10}$ The forced expiratory volume in one second $\left(\mathrm{FEV}_{1}\right)$ was measured in five cooperative patients only and the values obtained expressed as per cent of the normal values for age and sex (mean 66.4\%; range: $41 \cdot 1-78 \cdot 3 \%$ ).

The therapeutic programme consisted of postural drainage, aerosol treatment with mucolytics and/or antibiotics, pancreatic enzymes, and vitamins. No bronchodilator drugs $\left(\beta_{2}\right.$ agonists, theophylline) were prescribed.

Oesophageal $\mathrm{pH}$ was monitored for 24 hours with a $1.5 \mathrm{~mm}$ diameter flexible glass $\mathrm{pH}$ probe (Ingold). The probe was inserted through the nares, passed into the stomach to ensure that gastric acid was present, then positioned $87 \%$ of the distance from the tip of the nose to the gastro-oesophageal junction, the latter being determined according to the formula of Strobel et al. ${ }^{11}$ In all cases position of the electrode was checked by fluoroscopy. The electrode was calibrated at the beginning and end of each study at $\mathrm{pH} 4 \cdot 0$ and $7 \cdot 0$ with buffer solutions. If the $\mathrm{pH}$ drift exceeded $0.3 \mathrm{pH}$ unit, then the recording was discarded. A reference electrode was attached to the patient's chest. Oesophageal reflux was defined as a decrease in the $\mathrm{pH}$ to less than 4.0 for at least 15 seconds. Output from the $\mathrm{pH}$ probe was recorded on a modified Holter cassette recorder, which the patient carried on a belt (Proxima Light). All children were allowed to eat an unrestricted diet but snacks between meals were not allowed. The cassette recording was analysed by a computer program (Esophogram, Gastrosoft) on a IBM personal computer. The recording system had manual event markers. When pressed these markers enter an event specific code into the computer memory simultaneously with oesophageal $\mathrm{pH}$. respiratory disorders if the latter alter any of th antireflux barriers. ${ }^{12}$ An association between GOR and cystic fibrosis has been reported in recent years and it has been suggested that aspiration of regurgitated gastric contents may
Many studies have implied that gastroneurally mediated reflex bronchoconstriction secondary to irritation of oesophageal mucosa. ${ }^{1-4}$ Nevertheless, establishing a direct association difficult. ${ }^{5}$ Recently, it has also been proposed that GOR may exacerbate pre-existing chronic 
The mother of each patient was instructed to press the event markers and record in a personal diary the following events: (a) beginning and end of the meals, (b) symptom occurrence, and (c) sleeping and awake periods. The following parameters were evaluated during each 24 hour oesophageal $\mathrm{pH}$ probe study: number of GOR episodes, percentage of time that intraoesophageal $\mathrm{pH}$ was less than 4.0 (percentage of GOR), number of long lasting GOR episodes ( $\geqslant 5$ minutes), and mean duration of reflux episodes (minutes) (that is, the ratio between minutes of oesophageal acid exposure and number of GOR episodes). Measurement for each parameter was divided into awake and sleeping periods, and into intervals less than two hours (fed) and more than two hours after meals (fasting). In addition, intraoesophageal $\mathrm{pH}$ profile was inspected during periods of chest physiotherapy. Prolonged $\mathrm{pH}$ recordings obtained from patients with cystic fibrosis were compared with those from 10 age matched children who served as controls and are part of a larger study reported elsewhere. ${ }^{12}$ These subjects were all referred to our unit by their physicians and underwent prolonged $\mathrm{pH}$ study because of symptoms suggesting GOR disease. Three of the controls had feeding problems caused by maternal anxiety, four had recurrent functional abdominal pain, and three had irritable bowel syndrome.

Combined recording of oesophageal motility and $\mathrm{pH}$ was performed for two hours, on a separate day, after a three hour fasting period. Oesophageal motility was monitored using a manometric assembly that incorporated a $4 \mathrm{~cm}$ sleeve sensor and four other catheters whose lumina terminated in side orifices located $1 \mathrm{~cm}$ distal to the distal sleeve margin, at the proximal sleeve margin, and 2.5 and $5 \mathrm{~cm}$ proximal to the sleeve. The sleeve sensor was positioned so that it straddled the lower oesophageal sphincter; intragastric pressure was recorded by the side hole located at the distal margin of the sleeve; the side holes located at the proximal sleeve margin and $2.5 \mathrm{~cm}$ proximal to the sleeve recorded oesophageal body pressure. The lower oesophageal sphincter was localised using the station pull through method. Pressures were transmitted to external transducers (Beckman 4-327-C) whose output was recorded on a rectilinear ink writing polygraph (Beckman R611).

The perfusion apparatus utilised during this investigation was a high fidelity pneumohydraulic capillary infusion pump (Arnodorfer Med Spec). The compliance of this system was low, having a pressure rise rate greater than $\mathbf{4 0}$ $\mathrm{kPa}(300 \mathrm{~mm} \mathrm{Hg}) /$ second upon total occlusion at the individual catheter openings. A microphone attached to a DC coupler input was placed at the level of thyroid cartilage to detect swallows. A $1.6 \mathrm{~mm}$ diameter micro $\mathrm{pH}$ intraluminal electrode (Microelectrodes Inc) recorded intraoesophageal $\mathrm{pH}$ at a site corresponding to $87 \%$ of the distance nares to lower oesophageal sphincter. The electrode was connected to a Beckman pH meter (N39042) and the pH signals were recorded on the manometric polygraph. Function of the $\mathrm{pH}$ electrode was confirmed by checks with buffers of $\mathrm{pH} 4 \cdot 0$ and $7 \cdot 0$ at the start and end of each recording session.
The manometric assembly and $\mathrm{pH}$ electrode were taped securely at the nose and the subjects were studied in a recumbent supine position.

Lower oesophageal sphincter basal pressure was measured every minute by subtracting the corresponding gastric fundal pressure. The sphincter pressure was not calculated during and immediately after relaxations of the sphincter and in correspondence with abdominal straining as indicated by increase of the fundic pressure. Transient relaxation of the lower oesophageal sphincter was defined as appropriate or inappropriate if it occurred with or without a complete peristaltic sequence in the oesophageal body, respectively. Relaxation of the lower oesophageal sphincter was defined as complete if the lower oesophageal sphincter pressure fell to within $0.53 \mathrm{kPa}(4 \mathrm{~mm} \mathrm{Hg})$ or less of the end expiratory gastric pressure. After the occurrence of each episode of GOR we measured, in the distal oesophageal body, amplitude of primary peristalsis (defined as a peristaltic sequence preceded by a burst of activity from the neck microphone suggesting swallowing) and the incidence of non-specific oesophageal motor defects such as simultaneous, repetitive, or broad based waves. Amplitude of peristalsis was calculated as the pressure rise from baseline oesophageal pressure to peak pressure. Oesophageal primary peristalsis was defined as efficacious or inefficacious if it was able or not to raise intraluminal $\mathrm{pH}$ by at least $0.5 \mathrm{pH}$ unit, respectively. The combined $\mathrm{pH}$ and manometric data from patients with cystic fibrosis were compared with those from other groups of patients in whom the $\mathrm{pH}$-manometric study was performed in an identical fashion: 12 patients (mean age 3.5 years, range 6 months- 10 years) with symptomatic GOR, eight patients with oesophagitis documented by endoscopy and biopsy (mean age $7 \cdot 5$ years, range 5-11 years), and seven patients with GOR disease complicated by recurrent respiratory symptoms such as asthma or pneumonia (mean age 4 years, range 6 months- 12 years). In the latter patients respiratory symptoms were considered reflux related because they improved with adequate antireflux regimen.

Patients with cystic fibrosis and pathological GOR were treated for eight weeks with cisapride, a new non-dopamine receptor blocking prokinetic drug, and postural treatment consisting of a prone position raised by $30^{\circ}$. Cisapride was given orally before meals in a dose of 0.6 $\mathrm{mg} / \mathrm{kg} /$ day in three equally divided doses, eight hours apart. Three days after the end of the therapeutic trial patients underwent 24 hour intraoesophageal $\mathrm{pH}$ monitoring.

The study was approved by the ethical committee of our faculty and informed written consent was obtained from the parents. All data were expressed as mean (SD); the unpaired Student's $t$ test, Wilcoxon's signed rank test, and the $\chi^{2}$ test were used for statistical evaluation of data.

\section{Results}

The results of analysis of continuous intraoesophageal $\mathrm{pH}$ monitoring are shown in 
Table 1 Analysis of continuous oesophageal pH recordings in patients with cystic fibrosis and controls. Values given as mean $(S D)$

\begin{tabular}{|c|c|c|}
\hline & Cystic fibrosis & Controls \\
\hline $\begin{array}{l}\text { Overall record: } \\
\text { Time <pH } 4 \cdot 0(\%) \\
\text { Episodes lasting } \geqslant 5 \mathrm{~min} \\
\text { Mean duration }(\mathrm{min}) \\
\text { No of episodes }\end{array}$ & $\begin{array}{r}11 \cdot 20(0 \cdot 30) \\
8 \cdot 14(4 \cdot 60) \\
5 \cdot 01(2 \cdot 35) \\
38 \cdot 20(20 \cdot 10)\end{array}$ & $\begin{array}{c}1.85(0.82)^{*} \\
0.90(1.04)^{*} \\
3.01(0.23)^{* *} \\
12.90(8.66)^{*}\end{array}$ \\
\hline $\begin{array}{l}\text { Fed period: } \\
\text { Time <pH } 4.0(\%) \\
\text { Episodes lasting } \geqslant 5 \text { min } \\
\text { Mean duration (min) } \\
\text { No of episodes }\end{array}$ & $\begin{array}{r}4 \cdot 57(3 \cdot 67) \\
3 \cdot 64(4 \cdot 04) \\
3 \cdot 96(2 \cdot 85) \\
18 \cdot 70(14 \cdot 30)\end{array}$ & $\begin{array}{l}0.48(0.50)^{*} \\
0.10(0.30)^{*} \\
1.42(1.73)^{*} \dagger \\
5.60(7.48)^{* *}\end{array}$ \\
\hline $\begin{array}{l}\text { Fasting period: } \\
\text { Time < }<\mathrm{pH} 4.0(\%) \\
\text { Episodes lasting } \geqslant 5 \mathrm{~min} \\
\text { Mean duration (min) } \\
\text { No of episodes }\end{array}$ & $\begin{array}{c}6 \cdot 60(3 \cdot 78) \\
4 \cdot 57(2 \cdot 76) \\
5 \cdot 35(3 \cdot 16) \\
19 \cdot 70(10 \cdot 40)\end{array}$ & $\begin{array}{l}1.80(0.89)^{*} \\
0.80(0.97)^{* *} \\
2.86(2 \cdot 47) \dagger \\
7.30(5 \cdot 13)^{*}\end{array}$ \\
\hline $\begin{array}{l}\text { Awake period: } \\
\text { Time <pH } 4.0(\%) \\
\text { Episodes lasting } \geqslant 5 \mathrm{~min} \\
\text { Mean duration (min) } \\
\text { No of episodes }\end{array}$ & $\begin{array}{c}5 \cdot 80(4 \cdot 30) \\
4 \cdot 64(4 \cdot 55) \\
3 \cdot 71(1 \cdot 81) \\
30 \cdot 80(18 \cdot 80)\end{array}$ & $\begin{array}{r}1.06(0.78)^{*} \\
0.10(0.30)^{*} \\
2.33(1.33) \dagger \\
10.30(8.59)^{*}\end{array}$ \\
\hline $\begin{array}{l}\text { Sleeping period: } \\
\text { Time <pH } 4.0(\%) \\
\text { Episodes lasting } \geqslant 5 \mathrm{~min} \\
\text { Mean duration }(\mathrm{min}) \\
\text { No of episodes }\end{array}$ & $\begin{array}{l}5 \cdot 06(4 \cdot 86) \\
3 \cdot 50(3 \cdot 43) \\
6 \cdot 80(4 \cdot 50) \\
8 \cdot 85(6 \cdot 40)\end{array}$ & $\begin{array}{l}0.78(0.65)^{* *} \\
0.80(1.07)^{* *} \\
3.52(2.40)^{* *} \\
2.90(1.70)^{*}\end{array}$ \\
\hline
\end{tabular}

table 1 . In 12 patients with cystic fibrosis the per cent of time that distal oesophageal $\mathrm{pH}$ was less than 4.0 was $2 \mathrm{SD}$ greater than that in controls. As indicated in the table, an abnormal GOR was homogeneously distributed among the various phases of the temporal analysis of the $\mathrm{pH}$ tracings. During periods of chest physiotherapy intraoesophageal $\mathrm{pH}$ profile did not show an increased rate of reflux. The 12 patients with cystic fibrosis who had evidence of pathological GOR from measurement of $\mathrm{pH}$ underwent simultaneous oesophageal manometric and $\mathrm{pH}$ study. Basal lower oesophageal sphincter pressure in patients with cystic fibrosis, $2.9(0.9) \mathrm{kPa}(21.8(6.5) \mathrm{mm} \mathrm{Hg})$, did not significantly differ from that detected in patients with symptomatic GOR, $3 \cdot 2(0 \cdot 7) \mathrm{kPa}$ $(23.6(4.9) \mathrm{mm} \mathrm{Hg})$, and in patients with oesophagitis, $2.5(0.5) \mathrm{kPa}(18.7(4 \cdot 1) \mathrm{mm} \mathrm{Hg})$. Patients with GOR disease complicated by respiratory symptoms had a basal lower oesophageal sphincter pressure of $1.3(0.2) \mathrm{kPa}$ $(9 \cdot 7(1 \cdot 3) \mathrm{mm} \mathrm{Hg})$ that was significantly lower than that recorded in the other groups $(p<0.05)$. Intrathoracic to intra-abdominal pressure gradient was not significantly different in the various groups of patients: cystic fibrosis, $1.0(0 \cdot 3) \mathrm{kPa}(7 \cdot 6(2 \cdot 1) \mathrm{mm} \mathrm{Hg})$; GOR alone, $1.2(0.3) \mathrm{kPa}(8.7(1.9 \mathrm{~mm} \mathrm{Hg})$; oesophagitis, $1 \cdot 1(0.1) \mathrm{kPa}(8.0(0.9) \mathrm{mm} \mathrm{Hg})$; and GOR and respiratory disease, $1 \cdot 1(0 \cdot 1) \mathrm{kPa}(8 \cdot 3(0 \cdot 7) \mathrm{mm}$ $\mathrm{Hg})$. Patients with cystic fibrosis had a total of 75 episodes of acid reflux, whereas 86,84 , and 63 episodes of acid reflux were detected in patients with symptomatic GOR, oesophagitis, and GOR disease complicated by respiratory symptoms, respectively. The majority of episodes of acid GOR in cystic fibrosis patients $(53.3 \%)$, in patients with symptomatic GOR $(25.6 \%)$, and in patients with reflux oesophagitis $(51 \cdot 2 \%)$ were associated with an identifiable inappropriate transient lower oesophageal sphincter relaxation (fig 1). In patients with GOR disease and respiratory symptoms, gradual decrease of lower oesophageal sphincter pressure to very low values (lower oesophageal sphincter pressure drift) was the most prevalent mechanism accounting for $38 \cdot 1 \%$ of reflux episodes. The proportion of reflux episodes associated with the different types of reflux mechanism in the study groups is reported in table 2 . Episodes of inappropriate lower oesophageal sphincter relaxation associated with reflux were evenly distributed in all patients with cystic fibrosis.

Analysis of motor events of the oesophageal body during acid exposure showed that amplitude of primary peristalsis in patients with cystic fibrosis was $7 \cdot 1(2.9) \mathrm{kPa}(53.2(21.5) \mathrm{mm}$ $\mathrm{Hg}$ ) and significantly lower than in patients with symptomatic GOR, 9.3 (2.6) $\mathrm{kPa}(70.1$ $(19 \cdot 2) \mathrm{mm} \mathrm{Hg})(\mathrm{p}<0.05)$, but did not differ from that measured in patients with oesophagitis, $6 \cdot 4(1 \cdot 9) \mathrm{kPa}(47 \cdot 8(14 \cdot 1) \mathrm{mm} \mathrm{Hg})$ and in patients with GOR disease and respiratory symptoms, $8 \cdot 1(0.7) \mathrm{kPa}(60 \cdot 7(5 \cdot 1) \mathrm{mm} \mathrm{Hg})$. The ability of primary peristalsis to clear acid from the lumen of the oesophagus (percentage of waves capable to raise intraluminal $\mathrm{pH}$ by at least $0.5 \mathrm{pH}$ units) in cystic fibrosis patients $(53 \cdot 2 \%)$ was lower than in patients with symptomatic GOR $\left(70 \cdot 1 \%, \chi^{2} 7 \cdot 5, \mathrm{p}<0.01\right)$, but did

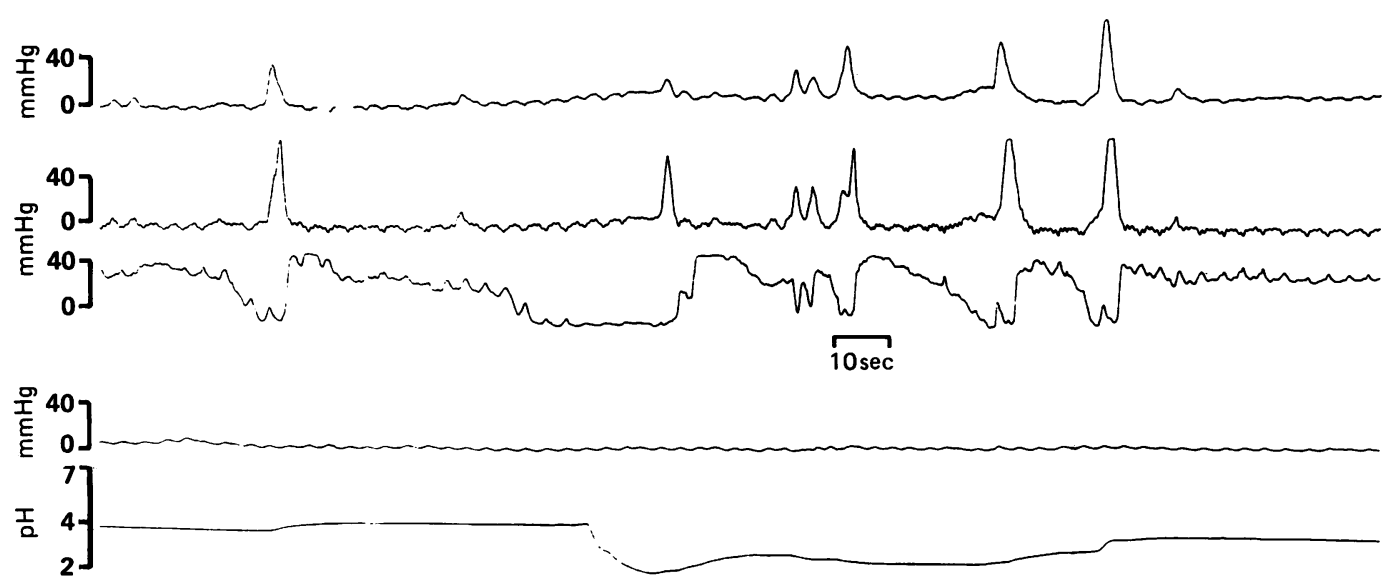

Figure 1 Combined oesophageal manometric and $\mathrm{pH}$ recording. From top to bottom: recording of swallowing, distal oesophageal body (two channels), lower oesophageal sphincter, fundus, and intraoesophageal pH. Episode of gastro-oesophageal reflux associated with an inappropriate lower oesophageal sphincter relaxation $(1 \mathrm{~mm} \mathrm{Hg=0} \cdot 133 \mathrm{kPa})$. 
Table 2 Percentage of reflux episodes associated with various pathogenetic mechanisms in the study groups

\begin{tabular}{|c|c|c|c|c|}
\hline & $\begin{array}{l}\text { Cystic } \\
\text { fibrosis } \\
(n=14)\end{array}$ & $\begin{array}{l}\text { GOR } \\
\text { alone } \\
(n=12)\end{array}$ & $\begin{array}{l}\text { Reflux } \\
\text { oesophagitis } \\
(n=8)\end{array}$ & $\begin{array}{l}\text { GOR with } \\
\text { respiratory } \\
\text { complications } \\
(n=7)\end{array}$ \\
\hline $\begin{array}{l}\text { Inappropriate LOS relaxations* } \\
\text { Appropriate LOS relaxations } \\
\text { Increased gastric pressure } \\
\text { Low LOS pressure† } \\
\text { Combined mechanisms } \ddagger\end{array}$ & $\begin{array}{c}53 \cdot 3 \\
14 \cdot 9 \\
8 \\
6 \cdot 6 \\
17 \cdot 3\end{array}$ & $\begin{array}{l}25 \cdot 6 \\
24 \cdot 4 \\
19 \cdot 7 \\
16 \cdot 3 \\
13 \cdot 9\end{array}$ & $\begin{array}{r}51 \cdot 2 \\
26 \cdot 2 \\
3 \cdot 6 \\
13 \cdot 1 \\
6 \cdot 0\end{array}$ & $\begin{array}{c}36 \cdot 5 \\
19 \cdot 0 \\
1 \cdot 6 \\
38 \cdot 1 \\
4 \cdot 76\end{array}$ \\
\hline
\end{tabular}

Cystic fibrosis $v$ GOR alone: ${ }^{*} \chi^{2} 11 \cdot 8, \mathrm{p}<0 \cdot 01$.

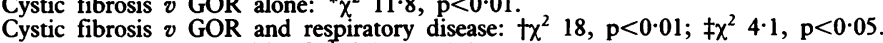

GOR alone $v$ oesophagitis: $\int \chi^{2} 5.49, \mathrm{p}<0 \cdot 01$.

GOR alone $v$ GOR and respiratory disease: $t \chi^{2} 7.9, p<0.01 ; \delta \chi^{2} 9.6, p<0.01$.

Oesophagitis $v$ GOR and respiratory disease: $t x^{2} 5 \cdot 2, p<0 \cdot 05$.

LOS, lower oesophageal sphincter.

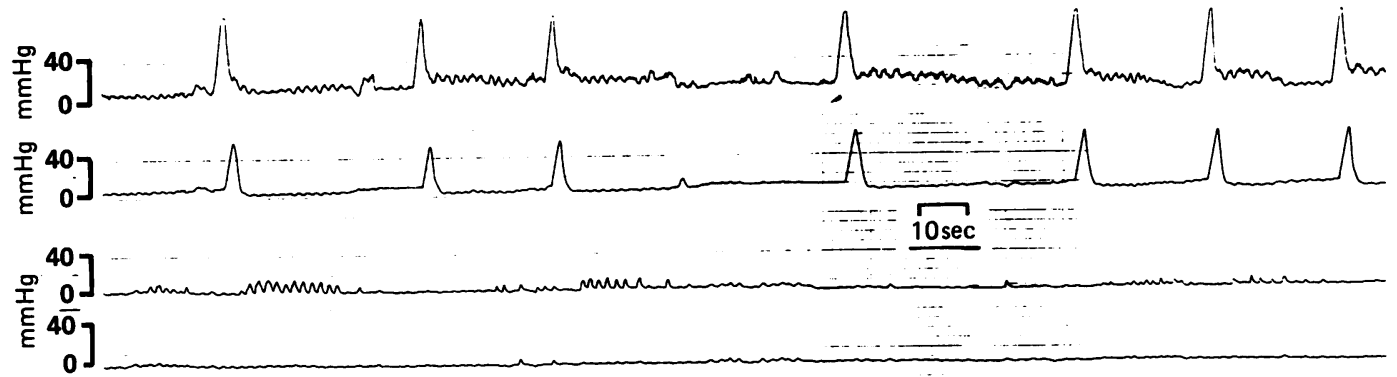

I $\left.\frac{7}{4}\right]$

Figure 2 Combined oesophageal manometric and pH recording. From top to bottom: recording of swallowing, distal oesophageal body (two channels), lower oesophageal sphincter, fundus, and intraoesophageal pH. Episode of gastro-oesophageal reflux associated with lower oesophageal sphincter decrease (1 $\mathrm{mm} H \mathrm{Hg}=0 \cdot 133 \mathrm{kPa}$ ).

Table 3 Prolonged intraoesophageal pH variables (\% of GOR and episodes lasting $\geqslant 5$ minutes) in seven children affected by cystic fibrosis and pathologic GOR treated with cisapride and postural treatment

\begin{tabular}{|c|c|c|c|c|c|c|c|c|c|c|}
\hline \multirow{2}{*}{$\begin{array}{l}\text { Case } \\
\text { Nos }\end{array}$} & \multicolumn{2}{|l|}{24 Hours } & \multicolumn{2}{|l|}{ Asleep } & \multicolumn{2}{|l|}{ Awake } & \multicolumn{2}{|l|}{ Fed } & \multicolumn{2}{|l|}{ Fasting } \\
\hline & $\% G O R$ & $\begin{array}{l}\text { Episodes } \\
\text { lasting } \\
\geqslant 5 \\
\text { minutes }\end{array}$ & $\% G O R$ & $\begin{array}{l}\text { Episodes } \\
\text { lasting } \\
\geqslant 5 \\
\text { minutes }\end{array}$ & $\% G O R$ & $\begin{array}{l}\text { Episodes } \\
\text { lasting } \\
\geqslant 5 \\
\text { minutes }\end{array}$ & $\% G O R$ & $\begin{array}{l}\text { Episodes } \\
\text { lasting } \\
\geqslant 5 \\
\text { minutes }\end{array}$ & $\% G O R$ & $\begin{array}{l}\text { Episodes } \\
\text { lasting } \\
\geqslant 5 \\
\text { minutes }\end{array}$ \\
\hline $\begin{array}{l}1 \\
2 \\
3 \\
4 \\
5 \\
6 \\
7 \\
\text { Mean } \\
\text { SD }\end{array}$ & $\begin{array}{r}18 \cdot 5 \\
9 \cdot 6 \\
15.5 \\
7.6 \\
7 \cdot 3 \\
6 \cdot 1 \\
10 \cdot 0 \\
10.6 \\
4.3\end{array}$ & $\begin{array}{r}14 \\
6 \\
4 \\
6 \\
6 \\
5 \\
6 \\
6 \cdot 7 \\
3 \cdot 0\end{array}$ & $\begin{array}{r}10 \cdot 2 \\
0.2 \\
11.9 \\
7 \cdot 2 \\
0.9 \\
0 \cdot 2 \\
2.0 \\
4.6 \\
4.6\end{array}$ & $\begin{array}{l}7 \\
0 \\
3 \\
5 \\
1 \\
0 \\
2 \\
2 \cdot 5 \\
2 \cdot 4\end{array}$ & $\begin{array}{l}\text { Baseline } \\
8 \cdot 3 \\
9 \cdot 3 \\
3 \cdot 6 \\
0 \cdot 4 \\
6 \cdot 3 \\
5 \cdot 9 \\
7 \cdot 9 \\
5 \cdot 9 \\
2 \cdot 8\end{array}$ & $\begin{array}{l}7 \\
6 \\
1 \\
1 \\
5 \\
5 \\
4 \\
4 \cdot 1 \\
2 \cdot 1\end{array}$ & $\begin{array}{l}8 \cdot 9 \\
4 \cdot 1 \\
6 \cdot 7 \\
1 \cdot 9 \\
2 \cdot 1 \\
2 \cdot 7 \\
5 \cdot 6 \\
4 \cdot 5 \\
2 \cdot 4\end{array}$ & $\begin{array}{l}6 \\
3 \\
2 \\
2 \\
1 \\
2 \\
3 \\
2 \cdot 7 \\
1 \cdot 5\end{array}$ & $\begin{array}{l}9 \cdot 5 \\
5 \cdot 4 \\
8 \cdot 8 \\
5 \cdot 6 \\
5 \cdot 1 \\
3 \cdot 3 \\
4 \cdot 3 \\
6 \cdot 0 \\
2 \cdot 1\end{array}$ & $\begin{array}{l}7 \\
3 \\
3 \\
4 \\
5 \\
3 \\
3 \\
4 \\
1 \cdot 4\end{array}$ \\
\hline $\begin{array}{l}1 \\
2 \\
3 \\
4 \\
5 \\
6 \\
7 \\
\text { Mean } \\
\text { SD }\end{array}$ & $\begin{array}{c}16.7 \\
1.1 \\
13.5 \\
3.2 \\
12.9 \\
0.04 \\
11.9 \\
8.47 \\
6.3\end{array}$ & $\begin{array}{c}18 \\
0 \\
10 \\
2 \\
7 \\
0 \\
7 \\
6.3 \\
5.9\end{array}$ & $\begin{array}{l}7 \cdot 0 \\
0 \\
0 \\
0 \cdot 8 \\
7 \cdot 1 \\
0 \cdot 04 \\
1 \cdot 8 \\
2 \cdot 39 \\
3 \cdot 0\end{array}$ & $\begin{array}{l}4 \\
0 \\
0 \\
2 \\
5 \\
0 \\
1 \\
1 \cdot 7 \\
1.9\end{array}$ & $\begin{array}{c}\text { After the } t \\
9 \cdot 7 \\
1 \cdot 1 \\
13.0 \\
2.3 \\
5.7 \\
0 \\
10 \cdot 1 \\
5.9 \\
4.6\end{array}$ & $\begin{array}{c}a l \\
14 \\
0 \\
10 \\
0 \\
2 \\
0 \\
6 \\
4 \cdot 5 \\
5 \cdot 2\end{array}$ & $\begin{array}{l}6 \cdot 7 \\
0 \cdot 05 \\
7 \cdot 1 \\
0 \cdot 7 \\
4 \cdot 0 \\
0 \\
8 \cdot 3 \\
3 \cdot 8 \\
3 \cdot 3\end{array}$ & $\begin{array}{c}10 \\
0 \\
6 \\
0 \\
1 \\
0 \\
6 \\
3 \cdot 3 \\
3 \cdot 7\end{array}$ & $\begin{array}{c}10.0 \\
1.1 \\
5.9 \\
2.5 \\
8.8 \\
0.04 \\
3.5 \\
4.5 \\
3.5\end{array}$ & $\begin{array}{l}8 \\
0 \\
4 \\
2 \\
6 \\
0 \\
1 \\
3 \\
2 \cdot 8\end{array}$ \\
\hline
\end{tabular}

not differ from that detected in oesophagitis patients $(42 \cdot 3 \%)$ and in GOR patients with respiratory complaints $(53 \cdot 6 \%)$. The incidence of non-specific motor defects during endogenous acid exposure in patients with cystic fibrosis $(17 \cdot 5 \%)$ was significantly higher than in symptomatic GOR patients $\left(8 \cdot 6 \% ; \chi^{2} 5 \cdot 1\right.$, $\mathrm{p}<0.05)$, but did not statistically differ from that recorded in the other study groups (oesophagitis 13.8\%, GOR and respiratory disease $9 \cdot 25 \%$ ).

Only seven patients with cystic fibrosis completed the eight week therapeutic course with cisapride and posture. Table 3 shows the before and after treatment values of both GOR percen- tage (oesophageal acid exposure time) and GOR episodes lasting more than five minutes for each patient, in the various phases of $\mathrm{pH}$ analysis. The oesophageal acid exposure time and the number of reflux episodes lasting more than five minutes became normal in only three patients and were unaffected in the other four patients.

\section{Discussion}

It is generally recognised that primary pulmonary disorders such as cystic fibrosis, bronchopulmonary dysplasia, or respiratory infections can provoke GOR. ${ }^{1}$ Both symptomatic and objectively documented reflux has been described in patients with cystic fibrosis. Scott $e t a l^{8}$ 
and Forster $e t a l^{7}$ detected by intraoesophageal $\mathrm{pH}$ measurement abnormal oesophageal acid exposure in a subgroup of cystic fibrosis patients complaining of symptoms of GOR; others have reported the presence of oesophageal injury from acid reflux in children with cystic fibrosis. ${ }^{69}$

The reason for an increased incidence of GOR in a wide variety of primary respiratory disorders is unknown. The most commonly considered mechanism is an increase of transdiaphragmatic pressure by the forced expiration of coughing and wheezing. ${ }^{1}$ It is also potentially possible that periodic coughing provokes GOR by intermittently raising abdominal pressure. Recent studies have revealed that active diaphragmatic contraction during spontaneous breathing is responsible for respiratory induced pressure oscillations of the lower oesophageal sphincter that are commonly observed during manometric evaluation of the sphincter. ${ }^{13}$ Furthermore, there is experimental evidence that contraction of crural diaphragm increases the barrier to movement across the gastrooesophageal sphincter. ${ }^{14}$ Therefore it is tempting to suggest that abnormalities in diaphragmatic performance might predispose the patient with primary respiratory disorders to the development of GOR. Our patients with cystic fibrosis and pathological GOR did not exhibit a decreased basal lower oesophageal sphincter pressure; furthermore, no disturbance in thoracoabdominal pressure gradient was detected in them. The predominant reflux mechanism in our cystic fibrosis patients was transient lower oesophageal sphincter relaxation, without a peristaltic sequence in the oesophageal body. Inappropriate transient lower oesophageal sphincter relaxations were also found to account for the majority of episodes of GOR in patients with symptomatic GOR and in patients with oesophagitis, whereas in patients with GOR related respiratory disease episodes of gradual decrease of basal lower oesophageal sphincter pressure were as common as transient lower oesophageal sphincter relaxation events. An excessively frequent rate of occurrence of spontaneous transient lower oesophageal sphincter relaxations is currently believed to be the most important abnormality that underlies pathological GOR. Gradual decrease of basal lower oesophageal sphincter tone has been shown to lead to reflux in a minority of patients. ${ }^{15}$

Triggers for transient lower oesophageal sphincter relaxation are not fully understood. Recently it has been suggested that transient inappropriate lower oesophageal sphincter relaxations are mediated by a neural mechanism involving active neural inhibition either by pharyngeal stimuli subthreshold for triggering a swallow or by sensory stimuli from the stomach. ${ }^{16}$ The high frequency of transient inappropriate relaxations of the lower oesophageal sphincter in our cystic fibrosis patients with pathologic GOR is consistent with experimental observations of Boyle et al-who have demonstrated that lung inflation provokes transient lower oesophageal sphincter relaxation by a reflex mechanism involving sensory input from vagal afferent fibres in the lung. ${ }^{17} 18$
Patients with pulmonary symptoms secondary to GOR showed a decreased basal lower oesophageal sphincter pressure compared with the other groups. However, their lower oesophageal sphincter pressure value is commonly considered to be sufficient to prevent GOR, also during episodes of increased intraabdominal pressure. ${ }^{19}$ Most reflux episodes in GOR related respiratory patients occurred during intermittent episodes of lower oesophageal sphincter pressure drift. Nevertheless, reflux episodes due to inappropriate lower oesophageal sphincter relaxations were also common in this population and their incidence did not statistically differ from that detected in cystic fibrosis patients. Both inappropriate lower oesophageal sphincter relaxation and lower oesophageal sphincter pressure drift are currently considered as intermittent episodes of deranged neural control of lower oesophageal sphincter pressure. ${ }^{15}$

During oesophageal manometry patients with GOR related respiratory complaints had both a normal pulmonary function and a normal chest $x$ ray picture; furthermore, none of them received bronchodilator treatment. These observations suggest that manometric patterns in these patients do not seem to be secondary to pulmonary disease.

Only seven patients with cystic fibrosis underwent a complete therapeutic course consisting of administration of a prokinetic drug, cisapride, and postural treatment. The prolonged intraoesophageal $\mathrm{pH}$ monitoring at the end of the trial showed that oesophageal acid exposure was not improved in the majority of patients. Indeed, if one assumes that in primary respiratory disorders, transient lower oesophageal sphincter inhibition can be induced by stimulation of pulmonary afferents, ${ }^{18}$ we suggest that unremitting chronic respiratory disorders might be a source of persisting lower oesophageal sphincter inhibition by a reflex mechanism. On the other hand, failure of cisapride to decrease oesophageal acid exposure in the majority of patients with cystic fibrosis who completed the therapeutic trial, can be explained by the lack of effects on the rate of transient lower oesophageal sphincter relaxation by the prokinetic drugs. ${ }^{20}$

The present study has confirmed that pathological GOR is common in cystic fibrosis patients. It appears to be a serious event because of the presence of both manometric abnormalities of the oesophageal body and significant degrees of nocturnal reflux; furthermore, medical treatment can be unsatisfactory. GOR should be properly investigated in children with cystic fibrosis through a complete medical interview and appropriate diagnostic tests such as prolonged intraoesophageal $\mathrm{pH}$ monitoring.

1 Orenstein SR, Orenstein DM. Gastroesophageal reflux and respiratory disease in children. F Pediatr 1988;112:847-58. of gastroesophageal reflux. Arch Intern Med 1985;145: 1882-8.

3 Nelson HS. Gastroesophageal reflux and pulmonary disease. Allergy Clin Immunol 1984;73:547-56.

4 Allen CJ, Newhouse MT. Gastroesophageal reflux and chronic respiratory disease. Am Rev Respir Dis 1984;129. 645-57. 
5 Boyle JT. Gastroesophageal reflux in the pediatric patient. Gastroenterology Clinics of North America 1989;18:315-7. Gastroenterology Clinics of North America 1989;18:315-7.
Bendig DW, Wagner ML, Harrison GM. Complications of gastroesophageal reflux in patients with cystic fibrosis. gastroesophageal reflux in

7 Forster AC, Voyles JB, Murphy SA. Twenty four hour pH monitoring in children with cystic fibrosis: association of chest physical therapy to gastroesophageal reflux. Pediatr

Res 1983;17:188.
8 Scott RB, O'Loughlin EV, Gall DG. Gastroesophageal reflux in patients with cystic fibrosis. F Pediatr 1985;106:223-7.

9 Vinecour CD, Marmon L, Schidlow DV, Weintraub WH. Gastroesophageal reflux in the infant with cystic fibrosis. Am F Surg 1985;149:182-6.

10 Chrispin AR, Norman AP. The systematic evaluation of the chest radiograph in cystic fibrosis. Pediatr Radiol 1974;2: $101-6$

11 Strobel CT, Byrne WJ, Ament Me, Euler AR. Correlation of esophageal lengths in children with height: application to the Tuttle test without prior esophageal manometry. $\mathcal{f}$ Pediatr 1979;94:81-4.

12 Cucchiara S, Staiano A, Gobio Casali L, Boccieri A, Paone FM. Value of the 24 hour intraoesophageal pH monitoring FM. Value of the 24 hour intraoesoph
in children. Gut 1990;31:129-33.

13 Boyle JT, Altschuler SM, Nixon TE, Tuchman DN, Pack $A \mathrm{~L}$, Cohen S. Role of the diaphragm in the genesis of the lower esophageal sphincter pressure in the cat. Gastroenterology 1985;88:723-30.
14 Williams TA, Altschuler SM, Hanna YJ, Boyle JT. Diaphragmatic contraction enhances the barrier to movemiant on ment across the gastroesophageal junction during

15 Dent J, Holloway RH, Touli J, Dodds WJ. Mechanism of lower oesophageal sphincter incompetence in patients with symptomatic gastrooesophageal reflux. Gut 1988;29. 1020-8.

16 Mittal RK, McCallum RW. Characteristics and frequency of transient relaxation of the lower esophageal sphincter in transient relaxation of the lower esophageal sphincter in
patients with reflux esophagitis. Gastroenterology 1988;95: 593-9.

17 Boyle JT, Altschuler SM, Patterson BL, Pack AL, Cohen S. Reflex inhibition of the lower esophageal sphincter (LES) following stimulation of pulmonary yagal afferent receptors. Gastroenterology 1986;90:1353.

18 Boyle JT, Patterson BL, Hanna Y. Reflex inhibition of the lower esophageal sphincter (LES) following stimulation of
bronchopulmonary non-myelinated c-fibers. Gastrobronchopulmonary
enterology 1988;94:46.

19 Dent J, Dodds WJ, Hogan WJ, Toouli J. Factors that influence induction of gastroesophageal reflux in norma human subjects. Dig Dis Sci 1988;33:270-5.

20 Reynolds JC. Prokinetic agents: a key in the future of gastroenterology. Gastroenterology Clinics of North America 1989, 18:437-57.

Towards a universal vaccine for atopy?

The possibility of a different and more fundamental kind of immunotherapy is raised by workers in Birmingham (Stanworth $e$ al, Lancet 1990;336:1279-81). A 10 amino acid peptide, which is part of the human IgE molecule, was synthesised and conjugated with protein. The peptide-protein conjugate was then used to immunise rabbits. The serum from these rabbits inhibited mast cell activation in rats. The authors showed firstly that the rabbit antiserum reduced the histamine release induced by incubating the rat mast cells with human $\varepsilon$ chain decapeptide solution. Secondly, they demonstrated that an intravenous injection of the antiserum inhibited the cutaneous reaction produced when rats given an intradermal injection of serum from rats sensitised to ovalbumin were injected intravenously with ovalbumin.

Immunisation of rats with the peptide-protein conjugate either before or after sensitising them to ovalbumin much reduced the serum histamine response to ovalbumin challenge and those immunised before sensitisation were protected from anaphylaxis induced by intravenous ovalbumin. A vaccine made from a rat peptide-protein conjugate had similar protective effects, being immunogenic possibly because the peptide is hidden within the IgE molecule and therefore not recognised as self. This gives hope that it might be possible to immunise people with the human peptide.

The authors suggest that clinical trials should now be carried out. There seems a long way to go before this work can be shown to apply to atopic patients but the potential is obvious and exciting. Future developments will be followed with very great interest.

ARCHIVIST 